BMJ Open

Diabetes

Research

\& Care

\title{
Association of unhealthy dietary behaviors with renal function decline in patients with diabetes
}

\author{
Cheng-Wei Lin (D) , ${ }^{1}$ I-Wen Chen, ${ }^{1}$ Ying-Tzu Lin, ${ }^{2}$ Hsin-Yun Chen, ${ }^{2}$ \\ Shih-Yuan Hung (D) ${ }^{1}$
}

To cite: Lin C-W, Chen I-W, Lin Y-T, et al. Association of unhealthy dietary behaviors with renal function decline in patients with diabetes. BMJ Open Diab Res Care 2020;8:e000743. doi:10.1136/ bmjdrc-2019-000743

C-WL and I-WC contributed equally.

Received 8 July 2019

Revised 19 November 2019

Accepted 10 December 2019
Check for updates

(c) Author(s) (or their employer(s)) 2020. Re-use permitted under CC BY-NC. No commercial re-use. See rights and permissions. Published by BMJ.

${ }^{1}$ Division of Endocrinology and Metabolism, Chang Gung Memorial Hospital Linkou Main Branch, Taoyuan, Taiwan ${ }^{2}$ Department of Medical Nutrition Therapy, Chang Gung Memorial Hospital Linkou Main Branch, Taoyuan, Taiwan

Correspondence to Dr Shih-Yuan Hung; 9002053@gmail.com

\section{ABSTRACT}

Objective Balanced nutrition is important for patients with diabetes, and nutrition might well influence diabetes-related complications, although there is limited evidence for this supposition at present. Consequently, we investigate the association between dietary behaviors and renal function decline among patients with diabetes.

Research design and methods From 2011 to 2013, a total of 2797 patients with type 2 diabetes participated in the Diabetes Shared Care Program at Chang Gung Memorial Hospital. All received nutritional consulting by dieticians and an eight-item list of unhealthy dietary behaviors, which included the excessive intake of carbohydrates, fats, protein, fruit, pickled foods, dessert and alcohol, as well as inadequate dietary vegetable. Estimated glomerular filtration rate (eGFR) decline $\geq 40 \%$ was defined as a surrogate end point for kidney damage. Independent dietary risk factors predicting poor renal outcomes were assessed.

Results Stable mean glycated hemoglobin $\left(A_{1 c}\right)(7.78 \%$ to $7.75 \%, p=0.151$ ), improved cholesterol (174.04 to $170.13 \mathrm{mg} / \mathrm{dL}, \mathrm{p}<0.001)$ and low-density lipoprotein (104.19 to $98.07 \mathrm{mg} / \mathrm{dL}, \mathrm{p}<0.001$ ) were found in patients throughout 2 years of therapy. However, significant eGFR decline was noted $\left(94.20\right.$ to $88.08 \mathrm{~mL} / \mathrm{min} / 1.73 \mathrm{~m}^{2}$, $\mathrm{p}<0.001)$. A total of 125 subjects had eGFR decline $\geq 40 \%$ and 2672 had stable renal progression.

In regression analysis, 625 stable renal patients (selected via propensity score matching) and 125 subjects with eGFR decline $\geq 40 \%$ demonstrated excessive pickled foods to be predictive of poor renal outcomes (OR 1.861, 95\% Cl 1.230 to $2.814, p=0.003$ ).

Conclusions Our study suggests that excessive pickled foods deteriorate renal function more than other unhealthy dietary behaviors in patients with diabetes.

\section{INTRODUCTION}

Worldwide comparisons demonstrate the prevalence of kidney disease to be more severe in Asia, especially in Taiwan, the country with the leading incidence rate of end-stage renal disease (ESRD). ${ }^{1}$ The incidence of ESRD has even increased while Taiwan has undergone medical service improvements. ${ }^{2}$ Diabetes mellitus is a major contributor to ESRD cases in Taiwan, accounting for $43.2 \% .^{3}$ Though the broad development of new antidiabetic

\section{Significance of this study}

What is already known about this subject?

- Prevalence of kidney diseases is more severe in Asia, especially in Taiwan, where diabetes mellitus is a major contributor to end-stage renal disease cases, accounting for nearly half of the patient population.

What are the new findings?

- Among unhealthy dietary behaviors, excessive pickled foods intake had the most impact on renal function decline in patients with diabetes even under stable metabolic control.

How might these results change the focus of research or clinical practice?

- Given the evidence that pickled foods would deteriorate renal function, sodium restriction should be flagged for renal protection with the precise amount requiring further research.

drugs has benefitted blood sugar control and decreased major adverse cardiac events and mortality, ${ }^{4-8}$ renal function decline has remained a serious problem for patients with diabetes.

The dietary behaviors in Taiwan are possibly associated with renal problems experienced by patients with diabetes. Several studies have investigated individual nutrient effects on renal function decline, including fat, protein, or sodium. ${ }^{9-12}$ However, few studies have focused on the association between dietary behaviors and renal function decline outcomes. This study investigated the influence of unhealthy dietary behaviors on rapid renal function decline.

\section{METHODS \\ Participants}

From 2011 to 2013, patients with type 2 diabetes mellitus, participating in the Diabetes Shared Care Program (DSCP) ${ }^{13}$ and attending the Chang Gung Memorial Hospital, a major medical center in Taiwan, were retrospectively 
analyzed. All patients received nutrition evaluation from professional dietitians during the 2-year study, with participants who were pregnant or diagnosed with ESRD being excluded. The Institutional Review Board of Chang Gung Memorial Hospital approved this study (No 104-9221B).

\section{Unhealthy dietary behaviors}

Eight unhealthy dietary behaviors were recorded, including excessive intake of dietary carbohydrate, fats, and protein; inadequate dietary vegetable; excessive fruit and pickled foods intake; and excessive dessert and alcohol consumption. Excessive carbohydrates, fats, and protein were defined as occupying more than $46 \%, 35 \%$, and $30 \%$ of total daily calories, respectively. Inadequate vegetable intake was defined as less than three servings per day, with one serving defined as a half-cup of cooked vegetables or one cup of raw vegetables. The definition of excessive fruit intake was eating more than three servings per day, with one serving of fruit defined as a small whole fruit (eg, a small apple) or about a half-cup of frozen or canned fruit. Excessive pickled food indicated eating pickled foods three times per week. Excessive dessert was defined as eating dessert three times per week. Excessive alcohol consumption was defined as more than three cups of alcohol drunk per week. ${ }^{14}$

The objective evaluation of eating behaviors was based on the standardized self-administered questionnaire provided by the DSCP, implemented nationally in Taiwan since 2001. To minimize reviewer bias, registered dietitians, certified by the Taiwan Dieticians Association and DSCP, performed the dietary behavior assessments.

\section{Clinical characteristics}

The clinical characteristics of patients, including age, gender, smoking habits, and comorbidities, such as hypertension, dyslipidemia, cardiovascular disease, heart failure, and cerebral vascular accidents were recorded beginning at their initial clinic visit. Laboratory data for glycemic control, lipids, and renal function were recorded at initial visits and for a 2-year follow-up period. Estimated glomerular filtration rate (eGFR) decline of more than $40 \%$ was defined as a surrogate end point for kidney disease progression. ${ }^{15}$

\section{Statistical analysis}

Categorical variables were reported as numbers with percentages, and continuous variables were reported as means with SD. Comparisons between the two groups were performed using Pearson's $\chi^{2}$ test for categorical variables or the Student's t-test for continuous variables, as indicated. A paired sample t-test was used to compare the biochemistry changes across the 2-year follow-up. All statistical tests were carried out at a two-tailed significance level of 0.05 using SPSS V.19 (IBM SPSS, Chicago, Illinois, USA).

Propensity score (PS) matching was executed to account for measured confounding. The PS used 1:5 matching stratified by age, gender, and variables known to
Table 1 Demographics and clinical characteristics of patients with diabetes with regularly clinic follow-up during 2011 to 2013

\begin{tabular}{lc}
\hline & Mean (SD) or $\mathbf{n}(\%)$ \\
\hline Patient numbers & 2797 \\
\hline Age (years) & $60.08(11.41)$ \\
\hline Gender & $1421(50.8)$ \\
\hline Male & $1376(49.2)$ \\
\hline Female & $333(11.9)$ \\
\hline Smoking & \\
\hline Comorbidities & $1686(60.3)$ \\
\hline Hypertension & $1200(42.9)$ \\
\hline Dyslipidemia & $75(2.7)$ \\
\hline Coronary heart disease & $20(0.7)$ \\
\hline Heart failure & $43(1.5)$ \\
\hline Cerebral vascular accident & \\
\hline Unhealthy dietary behaviors & $1412(50.5)$ \\
\hline Excessive carbohydrate & $902(32.2)$ \\
\hline Excessive protein & $1822(65.1)$ \\
\hline Excessive fat & $1077(38.5)$ \\
\hline Inadequate vegetable & $1178(42.1)$ \\
\hline Excessive fruit & $590(21.1)$ \\
\hline Excessive pickled food & $940(33.6)$ \\
\hline Excessive dessert & $237(8.5)$ \\
\hline Alcohol consumption & \\
\hline
\end{tabular}

influence renal outcome, including hypertension, dyslipidemia, initial glycemic and lipid control, and certain medications. Multivariate logistic regression analysis was used to find independent dietary factors predicting rapid renal function decline in PS-matched subjects.

\section{RESULTS}

In total, 2797 participants were enrolled in this study. The mean age was $60.08( \pm 11.41)$ years, and $50.8 \%$ of the patients were male (table 1). Hypertension was diagnosed in $39.0 \%$ of the patients, and $42.9 \%$ had dyslipidemia. The prevalence rates of coronary artery disease, heart failure, and stroke were $2.7 \%, 0.7 \%$, and $1.5 \%$, respectively, with current smokers accounting for $11.9 \%$ of these participants. Most had excessive carbohydrate $(50.5 \%)$ and excessive fat $(65.1 \%)$ intake. The next most common unhealthy dietary behaviors were excessive fruit $(42.1 \%)$, inadequate vegetable $(38.5 \%)$, excessive dessert $(33.6 \%)$, and excessive protein $(32.2 \%)$ intake. Excessive pickled food was recorded in $21.1 \%$ of the participants, and alcohol consumption was recorded only in $8.5 \%$ (table 1).

The diabetes control among these patients was moderate and remained stable over the 2-year follow-up period (glycated hemoglobin $\left(\mathrm{A}_{1 \mathrm{c}}\right)$ from $7.78 \%$ to $7.75 \%, \mathrm{p}=0.151$ ) with the lipid control receiving mild 
Table 2 Biochemistry changes across the 2-year follow-up in these 2797 patients with diabetes

\begin{tabular}{lccc}
\hline & Before & After & P value \\
\hline $\mathrm{A}_{1 \mathrm{c}}(\%)$ & $7.78(1.50)$ & $7.75(1.49)$ & 0.151 \\
Body mass index $\left(\mathrm{kg} / \mathrm{m}^{2}\right)$ & $25.98(4.05)$ & $25.96(3.91)$ & 0.841 \\
eGFR $\left(\mathrm{mL} / \mathrm{min} / 1.73 \mathrm{~m}^{2}\right)$ & $94.2(35.60)$ & $88.08(34.81)$ & $<0.001$ \\
Cholesterol level $(\mathrm{mg} / \mathrm{dL})$ & $174.04(35.62)$ & $170.13(47.16)$ & $<0.001$ \\
Triglyceride level $(\mathrm{mg} / \mathrm{dL})$ & $149.77(118.92)$ & $146.91(106.07)$ & 0.150 \\
HDL cholesterol level $(\mathrm{mg} / \mathrm{dL})$ & $46.06(11.56)$ & $45.36(11.73)$ & $<0.001$ \\
LDL cholesterol level $(\mathrm{mg} / \mathrm{dL})$ & $104.19(30.80)$ & $98.07(28.94)$ & $27.8(28.08)$ \\
ALT $(\mathrm{U} / \mathrm{L})$ & $27.92(26.48)$ & 0.835 \\
\hline
\end{tabular}

A1c, glycated hemoglobin; ALT, alanine aminotransferase; eGFR, estimated glomerular filtration rate; HDL, high-density lipoprotein; LDL, low-density lipoprotein.

improvement (cholesterol from 174.04 to $170.13 \mathrm{mg}$ / $\mathrm{dL}, \mathrm{p}<0.001$; low-density lipoprotein from 104.19 to $98.07 \mathrm{mg} / \mathrm{dL}, \mathrm{p}<0.001$, respectively). However, a deterioration of renal function, measured via eGFR decline (from $94.20 \mathrm{~mL} / \mathrm{min} / 1.73 \mathrm{~m}^{2}$ to $88.08 \mathrm{~mL} / \mathrm{min} / 1.73 \mathrm{~m}^{2}$, $\mathrm{p}<0.001$ ), was also documented (table 2). In total, 125 subjects had eGFR decline $\geq 40 \%$, and their clinical data were compared with the other 2672 subjects who had stable renal progression.

Patients with stable renal progression $(n=2672)$ had significantly lower prevalence of hypertension $(38.5 \%$ vs $51.2 \%, \mathrm{p}=0.004)$, a higher baseline eGFR $(94.75 \mathrm{~mL} /$ $\mathrm{min} / 1.73 \mathrm{~m}^{2}$ vs $\left.82.48 \mathrm{~mL} / \mathrm{min} / 1.73 \mathrm{~m}^{2}, \mathrm{p}=0.016\right)$, and improved $\mathrm{A}_{1 \mathrm{c}}$ values $(7.75 \%$ vs $8.60 \%, \mathrm{p}=2.05)$ compared with the 125 patients with rapid eGFR decline $\geq 40 \%$ (table 3). After PS matching, no statistical differences in age, gender, body mass index, comorbidities, or medications was shown between the two groups (table 3). Furthermore, among the 750 PS-matched subjects, excessive pickled food intake was the only independent risk factor to predict rapid eGFR decline (OR $1.861,95 \%$ CI 1.230 to $2.814, \mathrm{p}=0.003$; figure 1 ).

\section{DISCUSSION}

In this study, around $4.47 \%$ of patients had renal function decline even with stable glycemic and lipid control. During the 2-year follow-up, eGFRs were reduced by $6.12 \mathrm{~mL} / \mathrm{min} / 1.73 \mathrm{~m}^{2}$ (average decline $3.06 \mathrm{~mL}$ / $\mathrm{min} / 1.73 \mathrm{~m}^{2}$ per year), similar to a previous report in the diabetes population but less than that in the population without diabetes. ${ }^{16}$ Patients with rapidly declining eGFR also had higher prevalence of hypertension, worse glycemic control, and lower baseline eGFR, compatible with known risk factors for predicting renal deterioration. ${ }^{17} 18$ Interestingly, excessive pickled food intake was the only independent dietary risk factor to predict renal function decline for the patients with type 2 diabetes in this study.

Pickled foods are popular garnishes in many countries, and some of them are fermented products believed to have health benefits because of their antioxidant, antimicrobial, antifungal, anti-inflammatory, antidiabetic, and antiatherosclerotic activities. ${ }^{19}$ However, unlike western countries, pickled food in Asia always includes salted and pickled vegetables, fruits, and fish, but not fermented foods like yogurt or cheese. The salted pickled foods are therefore rich in sodium and thought to have adverse effects on renal function. The high sodium dietassociated renal damage involves a complex relationship between increased blood pressure, proteinuria, and higher intraglomerular pressure. The potential mechanisms included the activation of the local reninangiotensin-aldosterone system (RAAS), endogenous inhibitors of $\mathrm{Na} / \mathrm{K}$ ATPase, and epithelial damage in vascular and glomerulus by increasing oxidative stress and transforming growth factor beta-1 levels. ${ }^{11}{ }^{20}$ Our study provided additional evidence that pickled foods increase the odds for renal damage compared with other unhealthy dietary behaviors, and this is believed to be through association with the essentially high sodium content.

Currently, some evidence has demonstrated the benefits of reduced dietary salt for renal protection. $^{21} 22$ Though still controversial, dietary salt restriction for diabetic nephropathy ${ }^{23}{ }^{24}$ remains a common professional recommendation. ${ }^{25}$ Restricted salt intake has been shown to benefit blood pressure because of decreased volume retention and a potential escape from RAAS cycle-related adverse effects. ${ }^{21}{ }^{26}$ Good hypertension control also has strong evidence for preventing diabetic nephropathic deterioration. ${ }^{27}{ }^{28}$ In experimental studies, a low-sodium diet reduced proteinuria and the development of glomerulosclerosis. Additionally, renoprotective and cardioprotective effects due to medications of RAAS blockade were more predominant in patients with diabetes who received low-sodium diet (RENAAL (reduction of endpoints in NIDDM with the angiotensin II antagonist losartan) and IDNT (irbesartan diabetic nephropathy trial) ). ${ }^{29}{ }^{30}$ Nevertheless, the RAAS blockade confounding is minimal in this study, because we analyzed the impact of dietary behaviors by matching medications including RAAS blockade. 
Table 3 PS matching for patients with eGFR decline $\geq 40 \%$ in comparing patients with stable renal function

\begin{tabular}{|c|c|c|c|c|c|c|}
\hline & \multicolumn{2}{|c|}{ Before PS matching } & \multirow[b]{3}{*}{ P value* } & \multicolumn{3}{|c|}{ After PS matching } \\
\hline & \multirow{2}{*}{$\begin{array}{l}\begin{array}{l}\text { Stable renal } \\
\text { function }\end{array} \\
\mathrm{n}=2672\end{array}$} & \multirow{2}{*}{$\begin{array}{l}\text { eGFR decline } \\
\geq 40 \% \\
n=125\end{array}$} & & \multirow{2}{*}{$\begin{array}{l}\begin{array}{l}\text { Stable renal } \\
\text { function }\end{array} \\
n=625\end{array}$} & \multirow{2}{*}{$\begin{array}{l}\text { eGFR decline } \\
\geq 40 \% \\
\mathrm{n}=125\end{array}$} & \multirow[b]{2}{*}{$\mathbf{P}$ value } \\
\hline & & & & & & \\
\hline \multicolumn{7}{|l|}{ Characteristic } \\
\hline Age & $60.09(11.42)$ & $59.78(11.21)$ & 0.763 & $58.92(11.60)$ & $59.78(11.21)$ & 0.450 \\
\hline Male gender & 1355 (50.7\%) & $66(52.8 \%)$ & 0.648 & 343 (54.9\%) & $66(52.8 \%)$ & 0.670 \\
\hline Hypertension & 1028 (38.5\%) & 64 (51.2\%) & 0.004 & $356(57.0 \%)$ & 64 (51.2\%) & 0.236 \\
\hline Dyslipidemia & $1146(42.9 \%)$ & $54(43.2 \%)$ & 0.945 & $262(41.9 \%)$ & $54(43.2 \%)$ & 0.791 \\
\hline$A_{10}$ & $7.75(1.46)$ & $8.6(2.05)$ & $<0.001$ & $8.47(1.74)$ & $8.6(2.05)$ & 0.516 \\
\hline $\mathrm{BMI}$ & $25.95(4.01)$ & $26.51(4.77)$ & 0.133 & $26.6(4.3)$ & $26.51(4.77)$ & 0.831 \\
\hline eGFR & 94.75 (34.28) & $82.48(55.83)$ & 0.016 & $86.47(35.61)$ & $82.48(55.83)$ & 0.443 \\
\hline \multicolumn{7}{|l|}{ Medication } \\
\hline Sulfonylurea & $1276(47.8 \%)$ & 77 (61.6\%) & 0.002 & 371 (59.4\%) & 77 (61.6\%) & 0.641 \\
\hline Metformin & $1643(61.5 \%)$ & 71 (56.8\%) & 0.293 & 369 (59.0\%) & 71 (56.8\%) & 0.642 \\
\hline Acarbose & 240 (9.0\%) & 24 (19.2\%) & $<0.001$ & $101(16.2 \%)$ & 24 (19.2\%) & 0.405 \\
\hline Glinide & 104 (3.9\%) & $10(8.0 \%)$ & 0.023 & 43 (6.9\%) & $10(8.0 \%)$ & 0.656 \\
\hline TZD & $182(6.8 \%)$ & $5(4.0 \%)$ & 0.219 & 24 (3.8\%) & $5(4.0 \%)$ & 0.933 \\
\hline DPP4i & $750(28.1 \%)$ & $53(42.4 \%)$ & 0.001 & $261(41.8 \%)$ & 53 (42.4\%) & 0.895 \\
\hline Insulin & $340(12.7 \%)$ & 39 (31.2\%) & $<0.001$ & $167(26.7 \%)$ & 39 (31.2\%) & 0.306 \\
\hline RAAS blockadeł & 1147 (42.9\%) & 89 (71.2\%) & $<0.001$ & 446 (71.4\%) & 89 (71.2\%) & 0.971 \\
\hline Statin & 759 (28.4\%) & 38 (30.4\%) & 0.629 & $195(31.2 \%)$ & 38 (30.4\%) & 0.860 \\
\hline Fibrate & $148(5.5 \%)$ & $5(4.0 \%)$ & 0.46 & $30(4.8 \%)$ & $5(4.0 \%)$ & 0.699 \\
\hline
\end{tabular}

${ }^{*}$ Compare data between patients with stable renal function before PS matching $(n=2672)$ and patients with eGFR decline $\geq 40 \%$ ( $\left.n=125\right)$. †Compare data between patients with stable renal function by PS matching $(n=625)$ and patients with eGFR decline $\geq 40 \%$ ( $n=125)$. ‡RAAS blockade include ACE inhibitor, angiotensin receptor blocker or direct renin inhibitor.

A1c, glycated hemoglobin; BMI, body mass index; DPP4i, dipeptidyl peptidase-4 inhibitor; eGFR, estimated glomerular filtration rate; PS, propensity score; RAAS, renin-angiotensin-aldosterone system; TZD, thiazolidinedione.

Unlike the consensus of sodium intake, the appropriate amount of dietary protein remains inconsistent for patients with diabetic nephropathy. Two meta-analyses revealed that dietary protein restrictions prevented renal function decline. ${ }^{1231}$ By contrast, a third meta-analysis and a Cochrane systemic review both concluded that a lowprotein diet demonstrated no significant improvement in renal function. ${ }^{10}{ }^{32}$ Though the benefits of protein restriction are still debatable, dietary protein intake should be maintained at $0.8 \mathrm{~g} / \mathrm{kg} /$ day according to the American Diabetes Association. ${ }^{25}$ High dietary protein intake is thought to increase the nitrogen load, glomerular filtration rate, and renal hypertrophy. ${ }^{33}$ Malhotra et al also proved that increased dietary protein was
Unhealthy dietary behaviors Odds ratio 95\% CI

Excessive carbohydrate

Excessive protein

Excessive fat

Inadequate vegetable

Excessive fruit

Excessive pickled food

Excessive dessert

Alcohol consumption
0.711

1.089

0.946

1.084

1.179

1.861

0.778

0.668
0.468-1.082

0.716-1.656

0.609-1.467

0.718-1.637

0.785-1.769

1.230-2.814

0.506-1.197

0.315-1.420
$P$ value

0.111

0.690

0.803

0.701

0.427

0.003

0.254

0.295

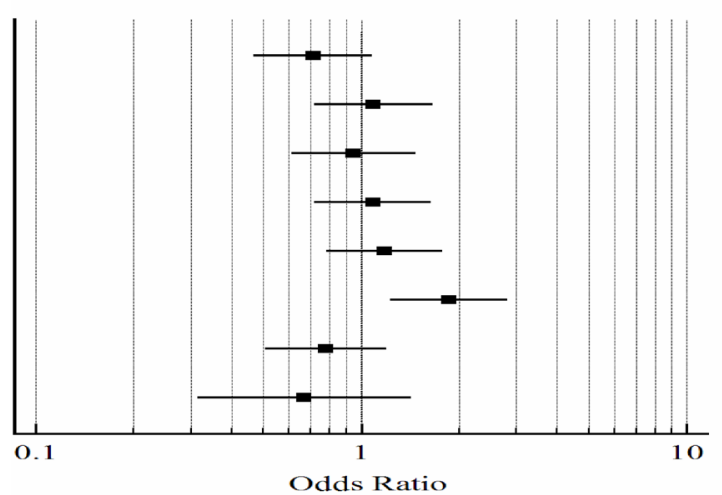

Figure 1 Forest plot of the impact of unhealthy dietary behaviors on rapid renal function decline via logistic regression model. Excessive pickled food intake independently predicted rapid renal function decline. 
associated with the incidence of end-stage kidney disease in patients with diabetes. ${ }^{34}$ This study also demonstrated that patients with diabetes with excessive dietary protein may increase the $8.9 \%$ incidence of eGFR decline, $\geq 40 \%$, but this finding was not statistically significant (OR 1.089, $95 \%$ CI 0.716 to $1.656, \mathrm{p}=0.690$ ).

Aggressive glycemic control has influenced diabetesrelated microvascular complications, including nephropathy in UK Prospective Diabetes Study, ${ }^{35}$ and advanced glycated end products are known to increase glucotoxicity, leading to kidney injury. ${ }^{36}$ In our study, excessive carbohydrate intake did not deteriorate renal function if glycemic control was performed well. In addition, other dietary factors, including a lipid-enriched diet, ${ }^{937}$ alcohol consumption, ${ }^{38}$ vegetables and fruit, ${ }^{39}$ had limited effects on renal function.

There were several limitations in this study. First, although dietary behaviors were analyzed, the amount of each dietary element was not quantified. Though we showed that pickled foods would deteriorate renal function, the precise amount of sodium restriction needed for renal protection requires further research. Additionally, the study population was limited to patients with diabetes, and therefore, the result cannot be generalized to a population without diabetes.

In conclusion, among the different unhealthy dietary behaviors analyzed, excessive intake of pickled foods had the most impact on renal function decline in patients with diabetes. Beyond glycemic and hypertension control, patients with diabetes should avoid such intake to prevent the deterioration of kidney function.

Contributors C-WL contributed to the study design and manuscript writing. I-WC contributed to the statistical analysis and wrote the manuscript. Y-TL and $\mathrm{H}-\mathrm{YC}$ collected the data and contributed to the discussion. S-YH reviewed the manuscript and gave the final approval of the version to be published.

Funding This study was supported by project grant from Chang Gung Memorial Hospital, Linkou (CMRPG3F1041).

Competing interests None declared.

Patient consent for publication Not required.

Provenance and peer review Not commissioned; externally peer reviewed.

Data availability statement All data relevant to the study are included in the article.

Open access This is an open access article distributed in accordance with the Creative Commons Attribution Non Commercial (CC BY-NC 4.0) license, which permits others to distribute, remix, adapt, build upon this work non-commercially, and license their derivative works on different terms, provided the original work is properly cited, appropriate credit is given, any changes made indicated, and the use is non-commercial. See: http://creativecommons.org/licenses/by-nc/4.0/.

ORCID iDs

Cheng-Wei Lin http://orcid.org/0000-0001-8922-7030

Shih-Yuan Hung http://orcid.org/0000-0002-9243-6586

\section{REFERENCES}

1 Wetmore JB, Collins AJ. Global challenges posed by the growth of end-stage renal disease. Renal Replacement Therapy 2016;2.

2 Tseng L-N, Tseng Y-H, Jiang Y-D, et al. Prevalence of hypertension and dyslipidemia and their associations with micro- and macrovascular diseases in patients with diabetes in Taiwan: an analysis of nationwide data for 2000-2009. J Formos Med Assoc 2012;111:625-36.

3 Hwang S-JYH, Tsai JER-C, Chen HC. Epidemiology, impact and preventive care of chronic kidney disease in Taiwan. Nephrology 2010;15:3-9.

4 Zinman B, Wanner C, Lachin JM, et al. Empagliflozin, cardiovascular outcomes, and mortality in type 2 diabetes. $N$ Engl $J$ Med 2015;373:2117-28.

5 Marso SP, Bain SC, Consoli A, et al. Semaglutide and cardiovascular outcomes in patients with type 2 diabetes. N Engl J Med 2016;375:1834-44.

6 Marso SP, Daniels GH, Brown-Frandsen K, et al. Liraglutide and cardiovascular outcomes in type 2 diabetes. $N$ Engl $J$ Med 2016;375:311-22.

7 Neal B, Perkovic V, Mahaffey KW, et al. Canagliflozin and cardiovascular and renal events in type 2 diabetes. N Engl J Med 2017;377:644-57.

8 Wiviott SD, Raz I, Bonaca MP, et al. The design and rationale for the Dapagliflozin Effect on Cardiovascular Events (DECLARE)-TIMI 58 Trial. Am Heart J 2018;200:83-9.

9 Aguila MB, Mandarim-de-Lacerda CA. Effects of chronic high fat diets on renal function and cortical structure in rats. Experimental and Toxicologic Pathology 2003;55:187-95.

10 Pan Y, Guo LL, Jin HM. Low-Protein diet for diabetic nephropathy: a meta-analysis of randomized controlled trials. Am J Clin Nutr 2008;88:660-6.

11 Wright JA, Cavanaugh KL. Dietary sodium in chronic kidney disease: a comprehensive approach. Semin Dial 2010;23:415-21.

12 Nezu U, Kamiyama H, Kondo Y, et al. Effect of low-protein diet on kidney function in diabetic nephropathy: meta-analysis of randomised controlled trials. BMJ Open 2013;3:e002934.

13 Kornelius E, Chiou J-Y, Yang Y-S, et al. The Diabetes Shared Care Program and risks of cardiovascular events in type 2 diabetes. Am J Med 2015;128:977-85.

14 American Diabetes Association. Standards of medical care in diabetes--2011. Diabetes Care 2011;34 Suppl 1:S11-61.

15 Badve SV, Palmer SC, Hawley CM, et al. Glomerular filtration rate decline as a surrogate end point in kidney disease progression trials. Nephrol. Dial. Transplant. 2016;31:1425-36.

16 Hemmelgarn BR, Zhang J, Manns BJ, et al. Progression of kidney dysfunction in the community-dwelling elderly. Kidney Int 2006;69:2155-61.

17 Sheen Y-J, Sheu WH. Risks of rapid decline renal function in patients with type 2 diabetes. World J Diabetes 2014;5:835-46.

18 Zoppini G, Targher G, Chonchol M, et al. Predictors of estimated GFR decline in patients with type 2 diabetes and preserved kidney function. CJASN 2012;7:401-8.

19 Şanlier N, Gökcen BB, Sezgin AC. Health benefits of fermented foods. Crit Rev Food Sci Nutr 2019;59:506-27.

20 Ying WZ, Sanders PW. Dietary salt modulates renal production of transforming growth factor-beta in rats. Am J Physiol 1998:274:F635-41.

21 Lambers Heerspink HJ, Navis G, Ritz E. Salt intake in kidney disease--a missed therapeutic opportunity? Nephrology Dialysis Transplantation 2012;27:3435-42.

22 Suckling RJ, He FJ, MacGregor GA, et al. Altered dietary salt intake for preventing and treating diabetic kidney disease. Cochrane Database Syst Rev 2010;52.

23 Ekinci El, Clarke S, Thomas MC, et al. Dietary salt intake and mortality in patients with type 2 diabetes. Diabetes Care 2011;34:703-9.

24 Thomas MC, Moran J, Forsblom C, et al. The association between dietary sodium intake, ESRD, and all-cause mortality in patients with type 1 diabetes. Diabetes Care 2011;34:861-6.

25 American Diabetes Association. 4. Lifestyle Management: Standards of Medical Care in Diabetes-2018. Diabetes Care 2018;41:S38-50.

26 Sacks FM, Svetkey LP, Vollmer WM, et al. Effects on blood pressure of reduced dietary sodium and the dietary approaches to stop hypertension (DASH) diet. DASH-Sodium Collaborative Research Group. N Engl J Med 2001;344:3-10.

27 Jindal A, Garcia-Touza M, Jindal N, et al. Diabetic kidney disease and the cardiorenal syndrome: old disease, new perspectives. Endocrinol Metab Clin North Am 2013;42:789-808.

28 Ruggenenti P, Perna A, Ganeva M, et al. Impact of Blood Pressure Control and Angiotensin-Converting Enzyme Inhibitor Therapy on New-Onset Microalbuminuria in Type 2 Diabetes: A Post Hoc Analysis of the BENEDICT Trial. JASN 2006;17:3472-81.

29 Brenner BM, Cooper ME, de Zeeuw D, et al. Effects of losartan on renal and cardiovascular outcomes in patients with type 2 diabetes and nephropathy. N Engl J Med Overseas Ed $2001 ; 345: 861-9$. 
30 Evans M, Bain SC, Hogan S, et al. Irbesartan delays progression of nephropathy as measured by estimated glomerular filtration rate: post hoc analysis of the irbesartan diabetic nephropathy trial. Nephrol Dial Transplant 2012;27:2255-63.

31 Kasiske BL, Lakatua JD, Ma JZ, et al. A meta-analysis of the effects of dietary protein restriction on the rate of decline in renal function. Am J Kidney Dis 1998;31:954-61.

32 Robertson LM, Waugh N, Robertson A, et al. Protein restriction for diabetic renal disease. Cochrane Database Syst Rev 2007;29.

33 Martin WF, Armstrong LE, Rodriguez NR. Dietary protein intake and renal function. Nutr Metab 2005;2.

34 Malhotra R, Cavanaugh KL, Blot WJ, et al. Higher protein intake is associated with increased risk for incident end-stage renal disease among blacks with diabetes in the southern community cohort study. Nutr Metab Cardiovasc Dis 2016;26:1079-87.
35 Robert T, Rury H, Carole C, et al. Intensive blood-glucose control with sulphonylureas or insulin compared with conventional treatment and risk of complications in patients with type 2 diabetes (UKPDS 33). The Lancet 1998;352:837-53.

36 Hasegawa S, Jao T-M, Inagi R. Dietary metabolites and chronic kidney disease. Nutrients 2017;9:358.

37 Malhotra R, Cavanaugh KL, Blot WJ, et al. Dietary polyunsaturated fatty acids and incidence of end-stage renal disease in the southern community cohort study. BMC Nephrol 2016;17:152.

38 White SL, Polkinghorne KR, Cass A, et al. Alcohol consumption and 5-year onset of chronic kidney disease: the AusDiab study. Nephrol Dial Transpl 2009;24:2464-72.

39 Gutiérrez OM, Muntner P, Rizk DV, et al. Dietary patterns and risk of death and progression to ESRD in individuals with CKD: a cohort study. Am J Kidney Dis 2014;64:204-13. 